\title{
Small animal PET imaging of the type 1 cannabinoid receptor in a rodent model for anorexia nervosa
}

\author{
Cindy Casteels • Nathalie Gérard • Kris van Kuyck • \\ Lies Pottel • Bart Nuttin • Guy Bormans • \\ Koen Van Laere
}

Received: 20 March 2013 / Accepted: 11 July 2013

(C) Springer-Verlag Berlin Heidelberg 2013

\begin{abstract}
Purpose Several lines of evidence strongly implicate a dysfunctional endocannabinoid system (ECS) in eating disorders. Using $\left[{ }^{18} \mathrm{~F}\right] \mathrm{MK}-9470$ and small animal positron emission tomography (PET), we investigated for the first time cerebral changes in type 1 cannabinoid (CB1) receptor binding in vivo in the activity-based rat model of anorexia (ABA), in comparison to distinct motor- and food-related control conditions and in relation to gender and behavioural variables.

Methods In total, experiments were conducted on 80 Wistar rats (23 male and 57 female). Male rats were assigned to the cross-sectional conditions: ABA $(n=12)$ and CONTROL $(n=11)$, whereas female rats were divided between two settings: (1) a cross-sectional design using $\mathrm{ABA}(n=13)$, CONTROL $(n=9)$, and two extra control conditions for each of the variables manipulated in ABA, i.e. DIET $(n=8)$ and WHEEL $(n=9)$, and (2) a longitudinal one using $\mathrm{ABA}(n=10)$ and CONTROL $(n=8)$ studied at baseline, during the model and upon recovery. The ABA group was subjected to food
\end{abstract}

Electronic supplementary material The online version of this article (doi:10.1007/s00259-013-2522-8) contains supplementary material, which is available to authorized users.

C. Casteels $(\bowtie) \cdot$ N. Gérard $\cdot$ L. Pottel $\cdot$ K. Van Laere

Division of Nuclear Medicine, University Hospital and KU Leuven,

Herestraat 49 bus 7003, 3000 Leuven, Belgium

e-mail: cindy.casteels@med.kuleuven.be

C. Casteels · N. Gérard · L. Pottel · G. Bormans · K. Van Laere Molecular Small Animal Imaging Center (MoSAIC), KU Leuven, Leuven, Belgium

K. van Kuyck • B. Nuttin

Laboratory for Experimental Functional Neurosurgery, KU Leuven, Leuven, Belgium

G. Bormans

Laboratory for Radiopharmacy, University Hospital and KU Leuven, Leuven, Belgium restriction in the presence of a running wheel, the DIET group to food restriction without wheel, the WHEEL group to a normal diet with wheel and CONTROL animals had a normal diet and no running wheel. Parametric CB1 receptor images of each group were spatially normalized to Paxinos space and analysed voxel-wise.

Results In the ABA model, absolute $\left[{ }^{18} \mathrm{~F}\right] \mathrm{MK}-9470$ binding was significantly increased in all cortical and subcortical brain areas as compared to control conditions (male $+67 \%$; female $>51 \%$, all $p_{\text {cluster }}<6.3 \times 10^{-6}$ ) that normalized towards baseline values after weight gain. Additionally, relative $\left[{ }^{18} \mathrm{~F}\right] \mathrm{MK}-9470$ binding was increased in the hippocampus, inferior colliculus and entorhinal cortex of female ABA $\left(+4.6 \% ; p_{\text {cluster }}<1.3 \times 10^{-6}\right)$, whereas no regional differences were observed in male subjects. Again, relative $\left[{ }^{18}\right.$ F]MK-9470 binding values normalized upon weight gain.

Conclusion These data point to a widespread transient disturbance of the endocannabinoid transmission, specifically for $\mathrm{CB} 1$ receptors in the ABA model. Our data also suggest (1) gender effects on regional $\mathrm{CB} 1$ receptor binding in the hippocampus and (2) add further proof to the validity of the ABA model to mimic aspects of human disease.

Keywords Type 1 cannabinoid receptor $\cdot$ Anorexia nervosa . ABA $\cdot$ Small animal PET $\cdot\left[{ }^{18} \mathrm{~F}\right] \mathrm{MK}-9470$

\section{Introduction}

Anorexia nervosa (AN) is a devastating psychiatric disorder characterized by abnormal patterns of feeding behaviour, severe weight loss, fear of gaining weight and distorted body perception [1]. Despite increasing knowledge of neurotransmitter system pathophysiology, few effective treatments exist 
for patients with AN and full recovery is seen in only $40-50 \%$ of patients [2].

Several lines of evidence point to an important role of the endocannabinoid system (ECS) in the control of food intake and in eating disorders. The brain ECS consists of a family of naturally occurring lipids, the endocannabinoids [of which anandamide (AEA) and 2-arachidonoylglycerol (2-AG) are the best characterized substances], of degradation proteins and of cannabinoid receptors [3]. The type 1 cannabinoid (CB1) receptor mediates the majority of cannabinoid effects on the central nervous system and is found in nearly all brain areas, especially those involved in controlling food intake and reward processing $[4,5]$. CB1 receptors are abundantly expressed presynaptically to directly or indirectly modulate major neurotransmitters such as glutamate, gammaaminobutyric acid (GABA) and dopamine [6, 7].

In AN patients, peripheral endocannabinoid levels are increased and negatively correlated to leptin [8], while after prolonged starvation in mice, brain levels of 2-AG have shown to decrease [9]. CB1 receptor knockout mice eat less after food deprivation and are leaner [10]. Also, different alleles of the CB1 receptor gene have been associated with restrictive and binging/purging subtypes of AN [11]. Polymorphisms of the gene coding for the endocannabinoid degrading enzyme fatty acid amide hydrolase (FAAH) have been associated both with anorexia and bulimia nervosa [12]. Furthermore, cannabis and cannabinoid agonists with minimal psychoactive side effect profile have been used as eating stimulants in acquired immunodeficiency syndrome (AIDS) or cancer patients [13]. Also, in animals, an orexigenic effect of $\mathrm{CB} 1$ receptor agonists is present, even in satiated condition [14]. However, in one clinical trial in primary AN, patients received high doses of cannabis' psychoactive component $\Delta^{9}$ tetrahydrocannabinol $\left(\Delta^{9}-\mathrm{THC}\right)$, but no improvement in food intake and body weight was observed [15], still necessitating the need for improved understanding of the ECS system in $\mathrm{AN}$ for future therapy guidance. In female AN patients, we recently found a profound cortical and subcortical increase of CB1 receptor availability in vivo [16].

So far, brain studies of EC changes in experimental models of AN have focused on the hypothalamus, hippocampus and brainstem, but have not assessed other regions [9, 17]. Also unknown is whether brain CB1 receptor levels are changed in anorectic conditions in vivo, as only in vitro, electrophysiological, behavioural and post-mortem data have been reported so far. In vivo imaging of CB1 receptors in rat brain has become feasible due to the development of CB1-selective positron emission tomography (PET) radioligands, such as $\left[{ }^{18} \mathrm{~F}\right] \mathrm{MK}-9470$ [18].

A well-characterized and frequently used rat model of AN $[19,20]$ relies on the use of a limited feeding period per day in combination with free access to a running wheel. After 710 days, rats display hyperactivity and spontaneously restrict the amount of food intake, leading to severe emaciation and often even death, to some extent modelling the behavioural aspects of AN [21]. The neuronal metabolic correlates of this model have previously been described using $\left[{ }^{18} \mathrm{~F}\right]$ fluorodeoxyglucose small animal PET, indicating changes in both motor and limbic circuitry $[22,23]$.

Our primary objective was to explore CB1 receptor changes in vivo using $\left[{ }^{18} \mathrm{~F}\right] \mathrm{MK}-9470$ and small animal PET in the activity-based rat model of AN (ABA). As a second objective, food intake, weight loss and motor activity, all shown to be altered in experimental AN [23], were investigated in the same animals and correlated to the regional CB1 receptor availability. To account for possible influence of gender or sex hormones, both female and male rats were studied cross-sectionally in separate designs. Finally, the reversibility of (possible) in vivo changes in $\mathrm{CB} 1$ receptor binding was longitudinally evaluated in female $\mathrm{ABA}$ rats until spontaneous weight recovery.

\section{Materials and methods}

Animals and model generation

All animal studies were reviewed and approved by the local Animal Ethics Committee and experiments were performed in compliance with the European Communities Council Directive of 24 November 1986 (86/609/EEC).

In total, experiments were conducted on 23 male and 57 female Wistar rats (on average 6 weeks old; body weight range at the start of the experiment 200-250 g and 108$200 \mathrm{~g}$, respectively). All rats were housed in groups of two with food and water available ad libitum until the start of the experiments. A 12-h light portion of the light/dark cycle beginning at $6.00 \mathrm{a} . \mathrm{m}$. was imposed.

Activity-based anorexia was induced in custom-made cages $(0.36 \times 0.36 \times 0.36 \mathrm{~m})$ with a running wheel (diameter $0.35 \mathrm{~m}$; Campden Instruments, Loughborough, UK; Cat. No. 80350 and $80850 ; 1$ wheel revolution equals $1.1 \mathrm{~m}$ ). An electromagnetic rotary encoder (TWK-Elektronik $\mathrm{GmbH}$, Düsseldorf, Germany; Cat. No. RBM22-06-64RK2P01) was mounted on the shaft of the running wheel for continuous registration of the position of the running wheel with a digital I/O card (National Instruments, Austin, TX, USA; Cat. No. DAQPad-6507) and LabVIEW 7.0 (National Instruments).

\section{Study design}

CB1 receptor binding was assessed in vivo in male Wistar rats using the following cross-sectional conditions: (1) an experimental group introduced in the ABA model, thus in cages with a fully functional running wheel $(n=12)$, and (2) a control group housed in similar cages but without food 
restriction and with the running wheel blocked (CONTROL, $n=11$ ). In addition, 39 of 57 female Wistar rats were crosssectionally divided between the following experimental settings: (1) ABA $(n=13)$ and (2) CONTROL $(n=9)$, as described above, and (3) DIET $(n=8)$ and (4) WHEEL $(n=9)$ to create a control condition for each of the two variables manipulated in the ABA model. The DIET group was subjected to food restriction with a blocked running wheel and the WHEEL group to a normal diet with a functional running wheel. Finally, the remaining female rats $(n=18)$ were used for assessment of reversibility in a separate longitudinal experiment and were randomized to ABA $(n=$ $10)$ and CONTROL $(n=8)$. Binding of $\left[{ }^{18} \mathrm{~F}\right] \mathrm{MK}-9470$ to the $\mathrm{CB} 1$ receptor was assessed in these animals at baseline, at a chronic time point during the model (day 10) and after spontaneous weight recovery upon renewed unrestricted eating. A schematic representation of all experimental designs is shown in Fig. 1.

All groups had access to $50 \mathrm{~g}$ of food starting at 8.30 a.m. The remainder of the food was removed and weighed at 10.00 a.m. for the groups on a restricted diet and at $8.30 \mathrm{a} . \mathrm{m}$. the next day for the groups on a normal diet. Weight restoration was performed by feeding all rats ad libitum again $(50 \mathrm{~g} / 24 \mathrm{~h})$. Water was always available. Body weight was measured daily at 10.00 a.m. Room temperature was kept constant at $\pm 20^{\circ} \mathrm{C}$. Daily food intake, relative weight loss, relative weight gain and running activity (number of wheel rotations) were monitored as covariates. For the female rats, vaginal cytological samples were systematically taken during 3 consecutive days, comprising the day of scanning. Early (pro-oestrus and oestrus) and late (dioestrus I and dioestrus II) phases of the ovarian cycle were determined by the type and number of different cells in the sample with light microscopy, as previously published [24].

\section{Radiotracer preparation and imaging}

CB1 receptor imaging was performed in all rats $(n=80)$ using the radioligand $\left[{ }^{18} \mathrm{~F}\right] \mathrm{MK}-9470((N-[2-(3-c y a n o-p h e n y l)-$ $3-\left(4-\left(2-\left[{ }^{18} \mathrm{~F}\right]\right.\right.$ fluoroethoxy $)$ phenyl)-1-methylpropyl]-2-(5methyl-2 pyridyloxy)-2-methylproponamide), which is characterized by high specificity and high affinity for the CB1 receptor (rat $\mathrm{IC}_{50}=0.9 \mathrm{nM}$ ) [25]. The precursor for tracer synthesis was obtained from Merck Research Laboratories (MRL, West Point, PA, USA) and labelling was performed using $\left[{ }^{18} \mathrm{~F}\right]$ fluoroethyl bromide, as described previously [18]. The final product was obtained after high-performance liquid chromatography (HPLC) purification and had a radiochemical purity $>95 \%$. Specific activity was on average $201 \mathrm{GBq} /$ $\mu \mathrm{mol}$ (specific activity range,53-606 GBq/ $\mathrm{mol}$ ). The tracer was administered in a sterile solution of $5 \mathrm{mM}$ sodium acetate buffer $\mathrm{pH} 5.5$ containing $6 \%$ of ethanol.
Image acquisition and reconstruction

Prior to small animal PET imaging, male rats were anaesthetized with $60 \mathrm{mg} / \mathrm{kg}$ sodium pentobarbital i.p. (Nembutal $^{\circledR}$, Ceva Santé Animale, Brussels, Belgium), while $2 \%$ isoflurane in 21 oxygen/min (Isoflurane USP ${ }^{\circledR}$, Abbott Laboratories Ltd., Maidenhead, UK) was used for female subjects due to logistic reasons. Previous work showed that both anaesthetics induced similar regional changes in the CB1 receptor binding of $\left[{ }^{18} \mathrm{~F}\right] \mathrm{MK}-9470$ in vivo as compared to non-anaesthetized animals [26]. Tail veins were catheterized for injection of $21.4 \pm 2.0 \mathrm{MBq}$ of $\left[{ }^{18} \mathrm{~F}\right] \mathrm{MK}-9470$ (specific activity range $100-760 \mathrm{GBq} / \mu \mathrm{mol}$; total volume of approximately $500 \mu \mathrm{l})$. After overnight fasting, $\left[{ }^{18} \mathrm{~F}\right] \mathrm{MK}-9470$ measurements were obtained during a 20-min interval, starting $1 \mathrm{~h}$ post-injection [25].

Small animal PET imaging was performed using a FOCUS 220 tomograph (Siemens/Concorde Microsystems, Knoxville, TN, USA), which has a transaxial resolution of $1.35 \mathrm{~mm}$ full-width at half-maximum. Data were acquired in a $128 \times 128 \times 95$ matrix with a pixel width of $0.475 \mathrm{~mm}$ and a slice thickness of $0.796 \mathrm{~mm}$. Sinograms were reconstructed using filtered backprojection (FBP) to avoid possible positive bias due to iterative methods [27]. No corrections were made for attenuation or scatter, due to the much smaller size of the rodent head and the lower thickness and density of the skull as compared to primates [28].

Image processing and data analysis

Parametric images based on (modified) standardized uptake values $((\mathrm{m}) \mathrm{SUV})(=$ activity concentration $(\mathrm{MBq} / \mathrm{ml}) \times($ (body mass $(\mathrm{g})+\mathrm{x}) / 2) /$ injected dose $(\mathrm{MBq}))$ were generated as a measure of absolute $\left[{ }^{18} \mathrm{~F}\right] \mathrm{MK}-9470$ binding. In the mSUV formula, body weight was extra normalized to the average body weight (x) of an adult Wistar rat, as determined on the strain's standard growth curve (male: $x=400$ g, female: $x=$ $250 \mathrm{~g}$ ) [29], to account for the systematic weight difference between anorectic and control rats. This index was previously validated to give reliable estimates of total volume of distribution as determined by full kinetic modelling in humans [30] and healthy rats [25]. Prior to study set-up, we also validated its use specifically for ABA. Full kinetic modelling in a small subset of ABA and control rats ( $n=2$ /group) showed a positive correlation of mSUV with total volume of distribution $\left(\mathrm{y}=90 \mathrm{x}-57 ; R^{2}=0.9\right)$. Also, $\mathrm{ABA}$ and control rats showed comparable $\left[{ }^{18} \mathrm{~F}\right] \mathrm{MK}-9470$ percentage fraction in arterial samples $(62.2 \pm 3.4 \%$ vs $58.4 \pm 9.5 \%$ and $12.8 \pm 7.4 \%$ vs $7.1 \pm 0.5 \%$ for $\mathrm{ABA}$ and control at 3 and 40 min postinjection, respectively). Non-parametric analysis did not detect significant differences in the AUC of the metabolitecorrected plasma input functions (Supplementary Fig. 1). 
Fig. 1 Cross-sectional (a) and longitudinal (b) experimental designs. $N$ number a

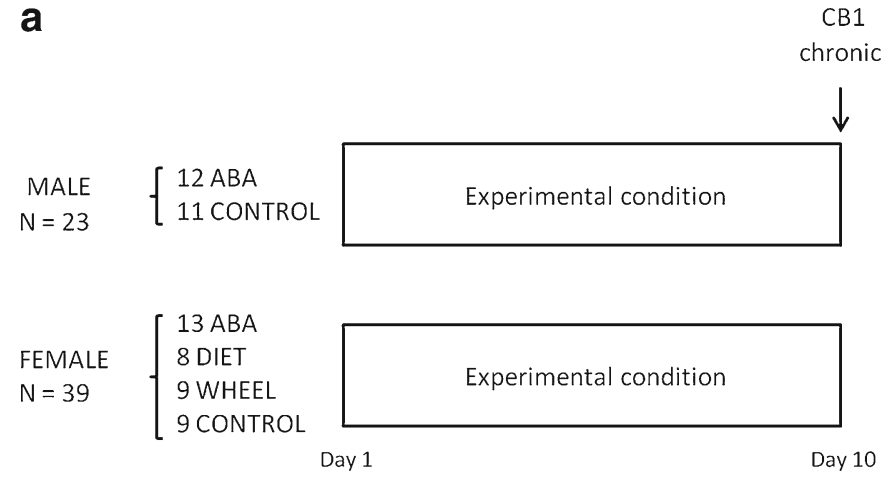

b

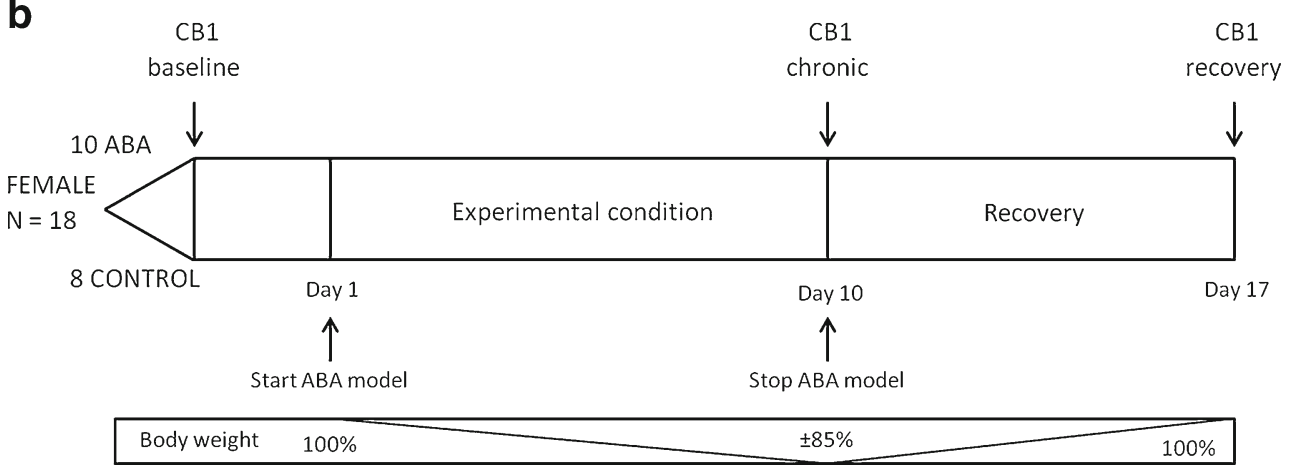

We investigated both absolute (mSUV) and relative $\left[{ }^{18} \mathrm{~F}\right] \mathrm{MK}-9470$ binding. Relative $\left[{ }^{18} \mathrm{~F}\right] \mathrm{MK}-9470$ binding was expressed as mSUV normalized on whole-brain mSUV. The within subject test-retest variability of our imaging procedure is consistent in magnitude with human data, i.e. $<5 \%$ [31].

To obtain maximal use of information without a priori knowledge, PET data were analysed voxel-wise using SPM2 (Statistical Parametric Mapping, Welcome Department of Cognitive Neurology, London, UK). For spatial normalization, individual PET data were standardized to custom-made rat brain templates in Paxinos stereotactic space [32]. This methodology allows reporting results in coordinates directly corresponding to the Paxinos coordinate system for the rat brain. Also, on this template, a predefined volume of interest (VOI) set of regions was defined for larger regional quantification purposes.

For SPM analysis, data were smoothed with an isotropic Gaussian kernel of $1.2 \mathrm{~mm}$ and analysed using a categorical subject design depending on gender (male: ABA vs CONTROL, and female: ABA vs CONTROL, WHEEL and DIET) and a condition $\mathrm{x}$ subjects interaction design for assessment of reversibility (conditions: baseline vs chronic vs recovery $\mathrm{x}$ subjects: ABA vs CONTROL). For analysis of absolute $\left[{ }^{18} \mathrm{~F}\right] \mathrm{MK}-9470$ binding, no proportional scaling was used and a relative (grey matter) analysis threshold of $80 \%$ was used to exclude extracerebral activity. For relative $\left[{ }^{18} \mathrm{~F}\right] \mathrm{MK}$ 9470 binding, proportional scaling was used with the same relative analysis threshold. In order to minimize false-positive findings, T-maps were interrogated at a peak voxel level of $p=0.001$ (uncorrected) and extent threshold $\mathrm{k}_{\mathrm{E}}>200$ voxels. Only significant clusters with $p<0.05$ (corrected for multiple comparisons) were retained, as described previously [33].

In addition, a within-group voxel-based correlation analysis between $\left[{ }^{18} \mathrm{~F}\right] \mathrm{MK}-9470$ uptake and the following covariates was performed in ABA: (1) body weight at the time of small animal PET scanning relative to starting weight, defined as body weight loss; (2) body weight at the time of recovery relative to chronic anorectic weight, defined as body weight gain; (3) average daily food intake; and (4) the total number of wheel rotations.

\section{General statistics}

Parametric unpaired Student's $t$ tests, analysis of variance (ANOVA) and correlation analysis for behavioural and VOI data were carried out using STATISTICA v8.0 (StatSoft, Tulsa, OK, USA). Tukey's HSD test was used for post hoc comparison. Significance was defined at the $95 \%$ probability level. Data are mean $\pm \mathrm{SD}$.

\section{Results}

Subjects and behavioural data

Body weight relative to starting weight or anorectic weight, food intake and wheel activity of all conditions over time are summarized in Figs. 2 and 3. 
MALE
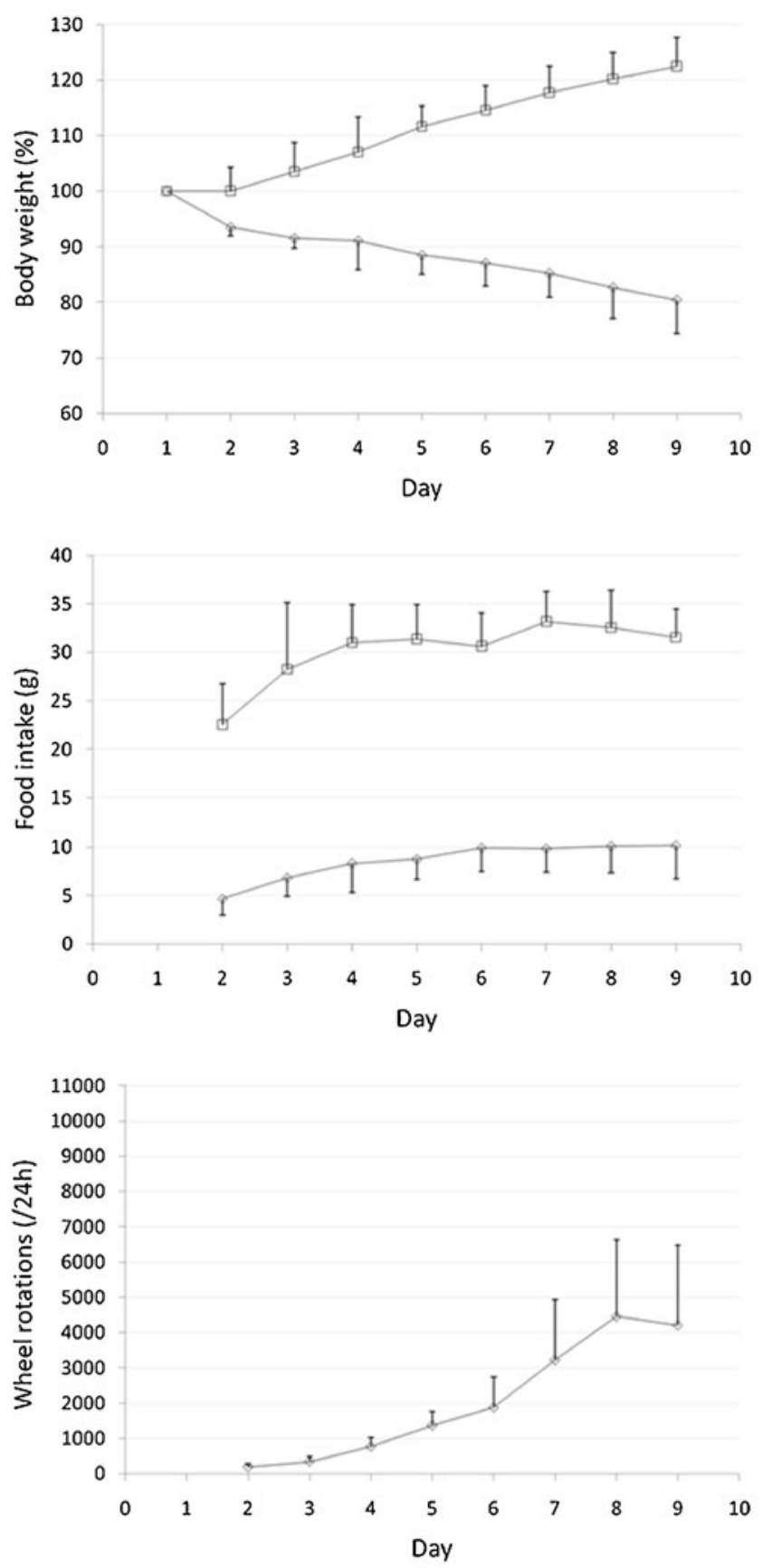

$\leadsto \mathrm{ABA} \nsucc$ DIET

Fig. 2 Behavioural data in male and female ABA. Comparison of relative body weight $(\%)$, food intake $(\mathrm{g})$ and number of wheel rotations $(/ 24 \mathrm{~h})$ between male (ABA-CONTROL) and female (ABA-DIETWHEEL-CONTROL) rats during the behavioural testing period. Mean

In male rats, body weight was significantly lower in the ABA group $(175 \pm 22 \mathrm{~g}$, mean $\pm \mathrm{SD})$ compared to the CONTROL group $(287 \pm 28 \mathrm{~g})$ on the day of PET scanning (day 9 relative to the start of the model; $p<0.00001$ ). Likewise, the
FEMALE
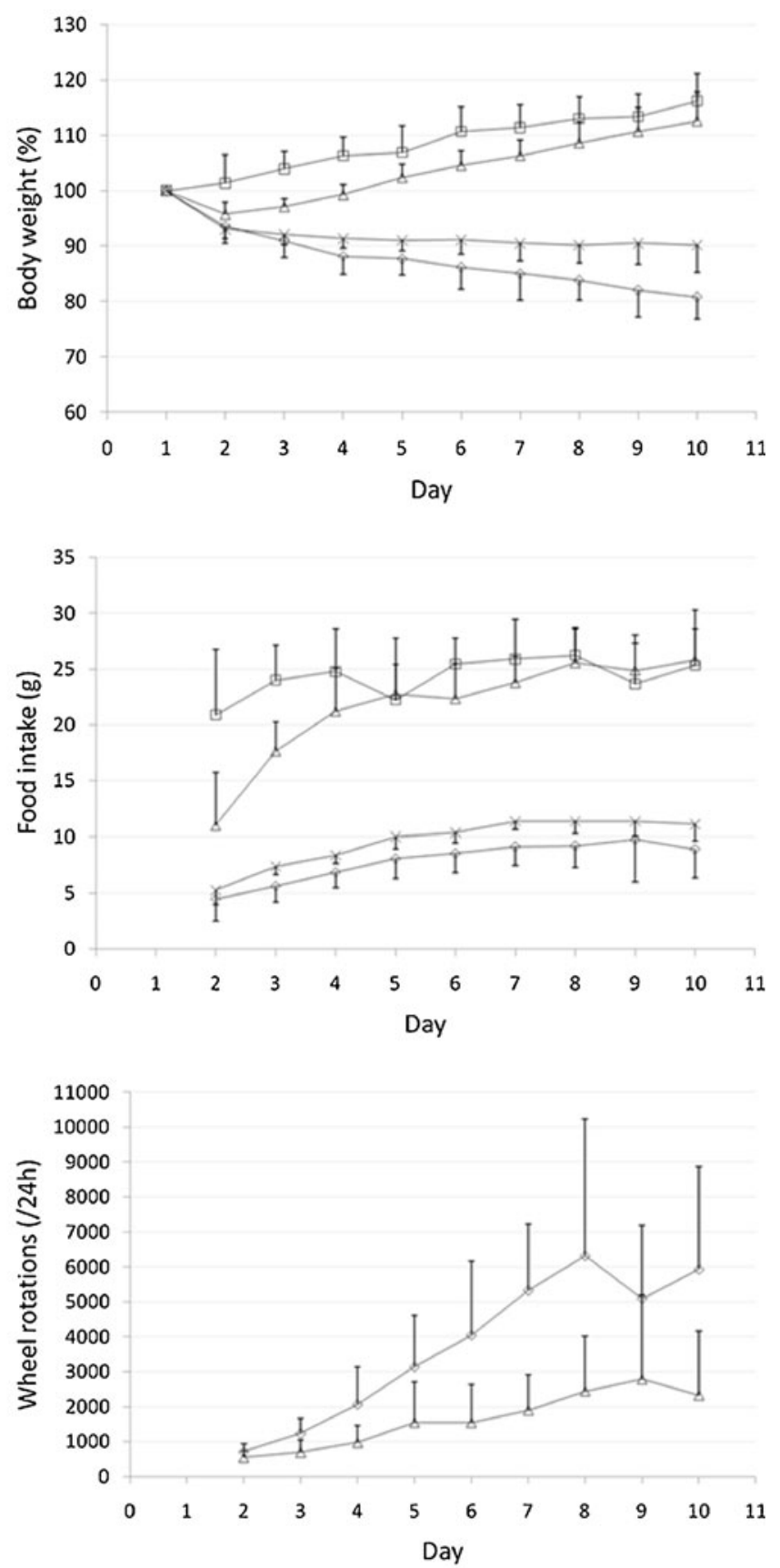

-WHEEL —-CONTROL

curves \pm 1 SD are given for each condition. CB1 receptor small animal PET scanning took place on day 9 and on day 10 for male and female rats, respectively, due to logistic reasons

ABA group had a significantly lower average daily food intake $(9 \pm 2 \mathrm{~g})$ during the testing period compared to the CONTROL group $(30 \pm 3 \mathrm{~g})(p<0.00001)$. The ABA rats completed 21,559 $\pm 7,147$ wheel revolutions during this 
BASELINE - CHRONIC
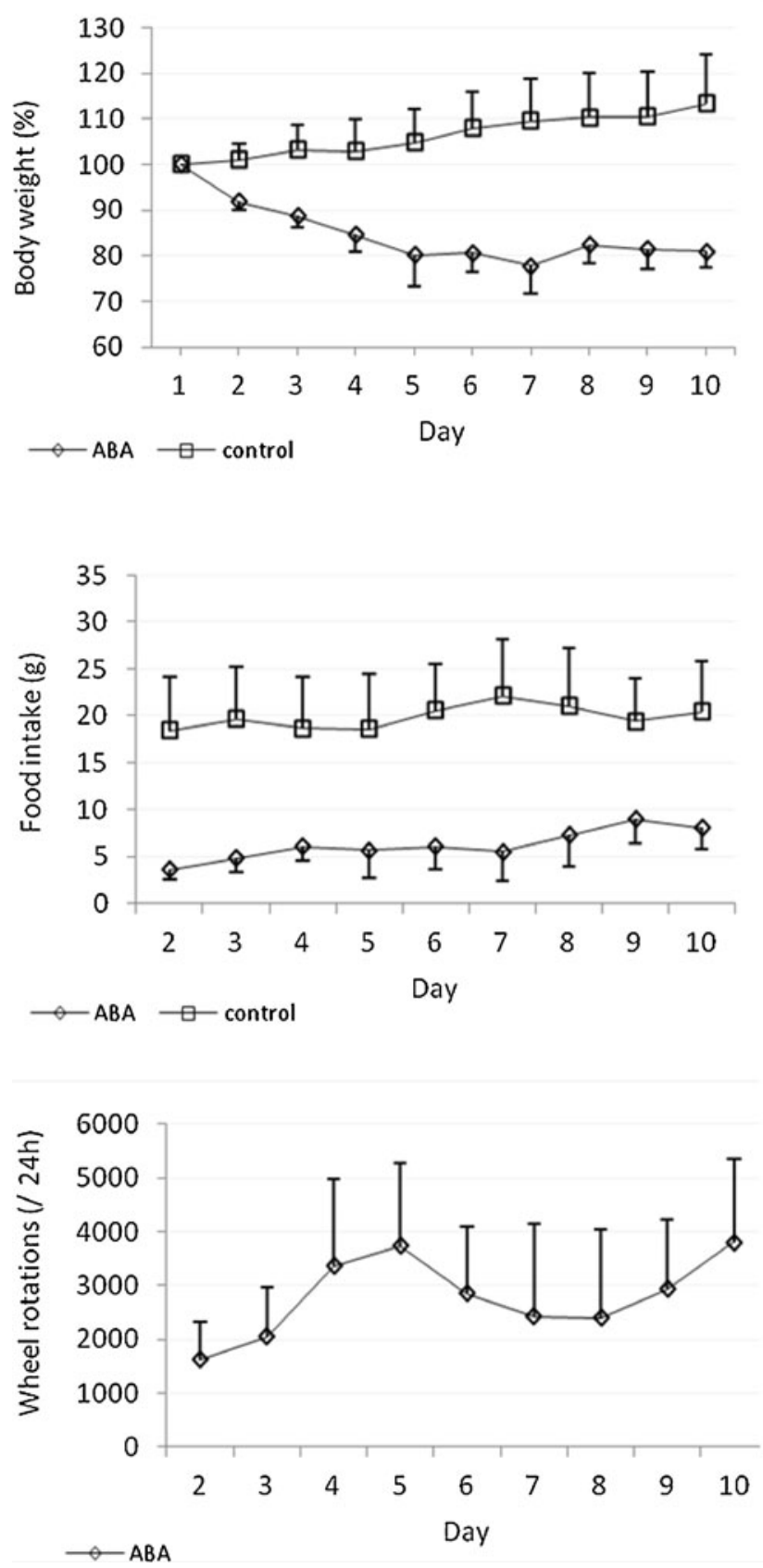

Fig. 3 Behavioural data in female ABA over time. Comparison of relative body weight $(\%)$, relative food intake $(\mathrm{g})$ and number of wheel rotations $(/ 24 \mathrm{~h})$ between female ABA and CONTROL during model development (left) and upon renewed unrestricted eating (right). Mean

testing period, which corresponds to a total distance of $23.7 \pm$ $7.9 \mathrm{~km}$.

At the time small animal PET scanning was performed on female Wistar rats in the cross-sectional design (day 10 relative to the start of the model), body weights of all four conditions were significantly different from each other $(p<0.00001)$. The average body weight for the ABA group was $130 \pm 12 \mathrm{~g}$, for the DIET group $149 \pm 13 \mathrm{~g}$, for the WHEEL

\section{CHRONIC-RECOVERY}
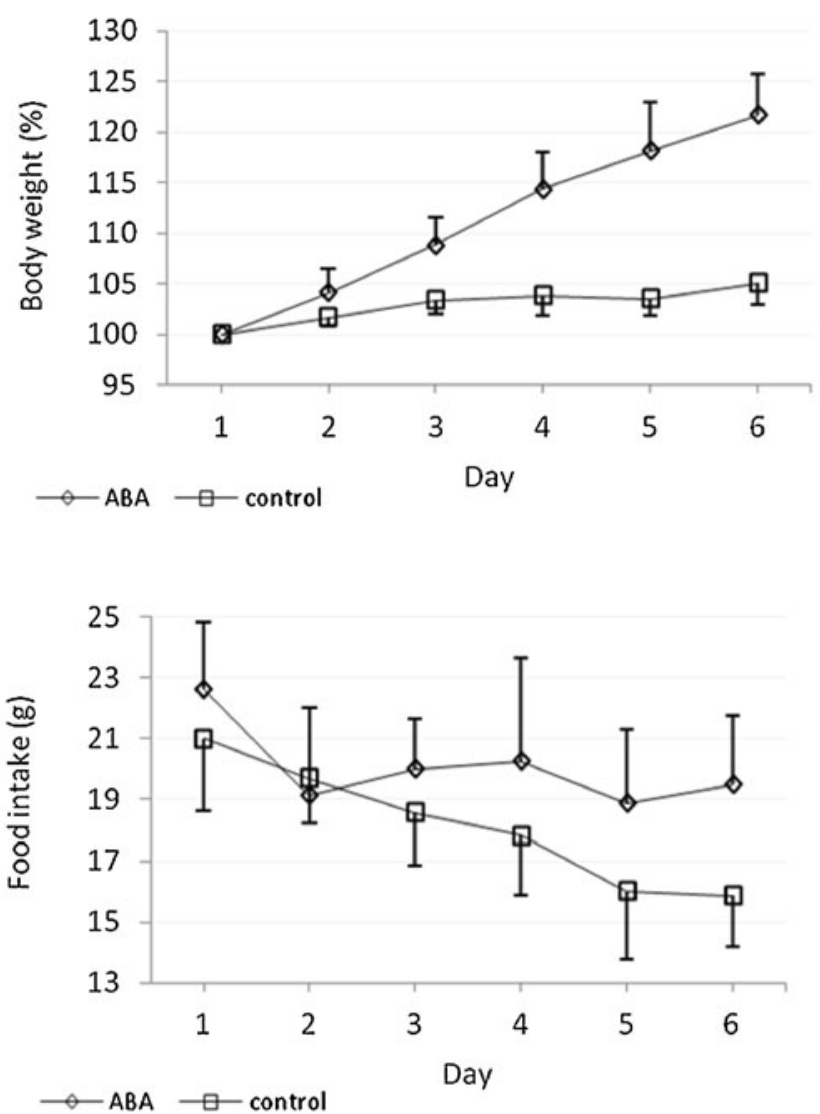

curves $\pm 1 \mathrm{SD}$ are given for each condition. Body weight is expressed relative to baseline weight on the left and relative to anorectic weight on the right

group $188 \pm 8 \mathrm{~g}$ and for the CONTROL group $204 \pm 8 \mathrm{~g}$. All groups also differed from each other in their average daily food intake, except for the ABA and DIET groups, which were the two food-restricted groups $(p<0.00001)$. The ABA group ate on average $8 \pm 2 \mathrm{~g}$, the DIET group $10 \pm 1 \mathrm{~g}$, the WHEEL group $22 \pm 2 \mathrm{~g}$ and the CONTROL group $24 \pm 2 \mathrm{~g}$ per day. In this design, two groups had a running wheel available; the number of wheel revolutions for ABA rats was 39,086 \pm 
$12,055(43 \pm 13.2 \mathrm{~km})$, which was significantly different from the $18,295 \pm 10,830$ rotations $(20.1 \pm 11.9 \mathrm{~km})$ ran by the WHEEL rats $(p<0.00001)$.

In the experimental set-up used for assessment of reversibility, female Wistar rats assigned to the ABA and CONTROL groups did not differ significantly in body weight at the time of baseline $\left[{ }^{18} \mathrm{~F}\right] \mathrm{MK}-9470$ small animal PET $(126 \pm 14 \mathrm{~g}$ and $125 \pm 17 \mathrm{~g}$, respectively). At the chronic time point, average body weight and food intake of ABA in comparison to CONTROL was $108 \pm 13 \mathrm{~g}$ vs $142 \pm 30 \mathrm{~g}$ and $6 \pm 3 \mathrm{~g}$ vs $20 \pm$ $5 \mathrm{~g}$, respectively. ABA rats ran during the 10 days in the model $27,838 \pm 7,910$ wheel rotations, which represents $30.6 \pm$ $8.7 \mathrm{~km}$. Upon renewed unrestricted eating, ABA rats increased their weight by on average $17 \%$, compared to the weight at the chronic scan, and CONTROLS by $4 \%$, a difference which was significant from day $2(p<0.05)$. Food intake in the CONTROL group decreased over time in comparison to the $\mathrm{ABA}$ rats, the first eating $18 \pm 3 \mathrm{~g}$ and the latter $20 \pm 3 \mathrm{~g}$.

On the day of chronic scanning in the ABA and DIET groups, 1 rat was in the early ovarian cycle phase compared to 19 and 7 rats in the late phase, respectively. In the WHEEL group, two rats were in the early phase and six in the late phase, while in the CONTROL group six were in the early phase and four in the late phase. Upon recovery, four ABA rats were found in the early ovarian cycle phase and three in the late phase, while five CONTROL rats were also in the latter one. Rats in the transition between early and late phases were not considered.

Categorical and interaction comparisons of small animal $\left[{ }^{18} \mathrm{~F}\right] \mathrm{MK}-9470$ PET

Absolute $\left[{ }^{18} \mathrm{~F}\right] \mathrm{MK}-9470$ binding was significantly increased in the whole brain of male ABA rats compared to CONTROL rats (average difference $67 \%, p_{\text {cluster }}=6.3 \times 10^{-6}$ ). Absolute binding of $\left[{ }^{18} \mathrm{~F}\right] \mathrm{MK}-9470$ to the $\mathrm{CB} 1$ receptor was also significantly increased in all cortical and subcortical areas in the female ABA group compared to WHEEL and CONTROL groups. The increases amounted to $+51 \%\left(p_{\text {cluster }}=7.6 \times 10^{-8}\right)$ and $+53 \%\left(p_{\text {cluster }}=8 \times 10^{-8}\right)$, respectively. The increase in absolute $\left[{ }^{18} \mathrm{~F}\right] \mathrm{MK}-9470$ binding in ABA compared to DIET $(+20 \%)$ was not significant, nor were the other group comparisons. In the experimental set-up used for assessment of reversibility, absolute $\left[{ }^{18} \mathrm{~F}\right] \mathrm{MK}-9470$ binding significantly increased between baseline and chronic phase $\left(+36 \%, p_{\text {cluster }}<\right.$ $2.5 \times 10^{-5}$ ) in all cortical and subcortical regions of ABA rats as compared to CONTROL, while absolute $\left[{ }^{18} \mathrm{~F}\right] \mathrm{MK}-9470$ binding subsequently decreased again in these regions of $\mathrm{ABA}$ upon recovery. No significant differences were noted for recovery versus baseline between both groups. Figure 4 shows the average images of absolute $\left[{ }^{18} \mathrm{~F}\right] \mathrm{MK}-9470$ binding in all experimental conditions, overlaid on a T2-weighted MR template. As can be seen from this figure, the pattern of $\left[{ }^{18} \mathrm{~F}\right] \mathrm{MK}$ 9470 uptake observed in the rat control brain is similar to that previously reported ex vivo [34], i.e. a fairly uniform and high uptake in the cortex, cerebellum and caudate-putamen. Figure 5 shows absolute $\left[{ }^{18} \mathrm{~F}\right] \mathrm{MK}-9470$ binding in a regional VOI bar plot during anorectic state where the significant increases in all regions were confirmed $(p<0.0001)$.

When looking at regional changes by relative scaling to the global mean tracer binding, no differences in relative $\left[{ }^{18} \mathrm{~F}\right] \mathrm{MK}-9470$ binding were found in male rats. However, in female rats, a regional increase was detected in the ABA group compared to the CONTROL $\left(+4.6 \%, p_{\text {cluster }}<\right.$ $1.3 \times 10^{-6}$; Fig. $\left.6 \mathrm{a}\right)$ and WHEEL $\left(+2.8 \%, p_{\text {cluster }}<3.1 \times 10^{-5}\right.$; Fig. 6b) groups using the voxel-based and VOI-based approach. These increases encompassed the hippocampus, the visual and entorhinal cortex, cerebellum and inferior colliculus. The hippocampal increase was also found in the

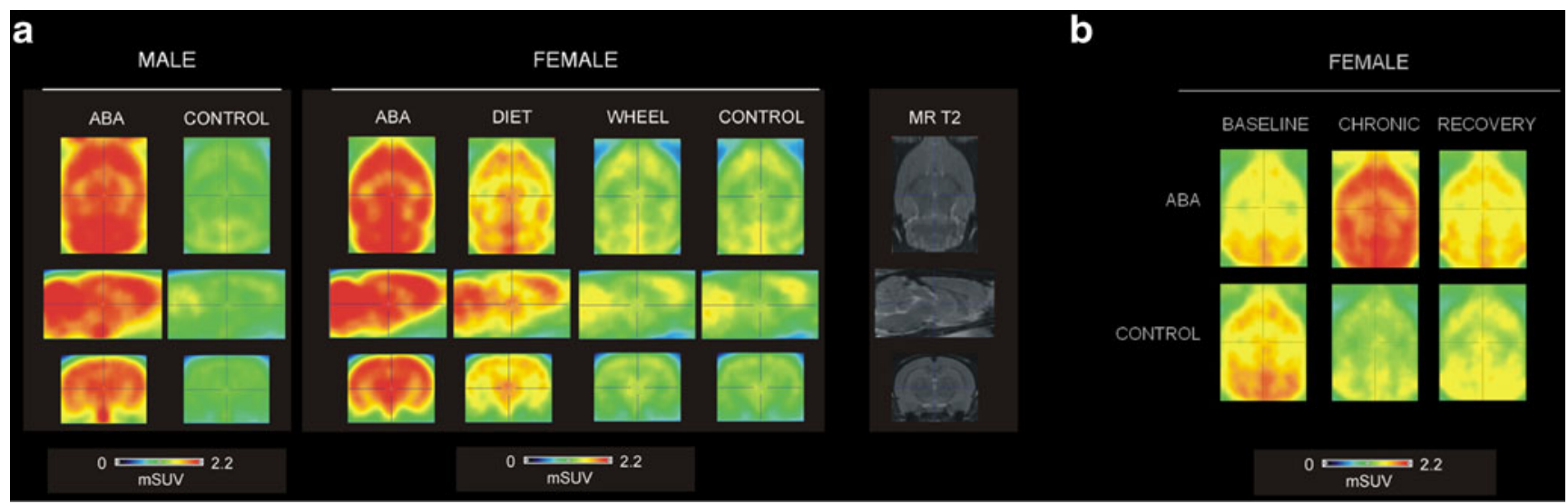

Fig. 4 Mean $\left[{ }^{18} \mathrm{~F}\right] \mathrm{MK}-9470$ in ABA. a Coronal, transverse and sagittal brain slices of absolute $\left[{ }^{18} \mathrm{~F}\right] \mathrm{MK}-9470$ binding in the rat brain of male ABA and CONTROL animals (left) and of female ABA, DIET, WHEEL and CONTROL animals (middle). As reference, a T2-weighted MR image oriented in Paxinos space is shown on the right side. b Transverse brain slices of absolute $\left[{ }^{18} \mathrm{~F}\right] \mathrm{MK}-9470$ binding in the rat brain of female ABA and CONTROL animals at baseline, at a chronic time point during the model and after spontaneous weight recovery. Mean images for the whole group are shown, with the intensity shown at a fixed mSUV scale 

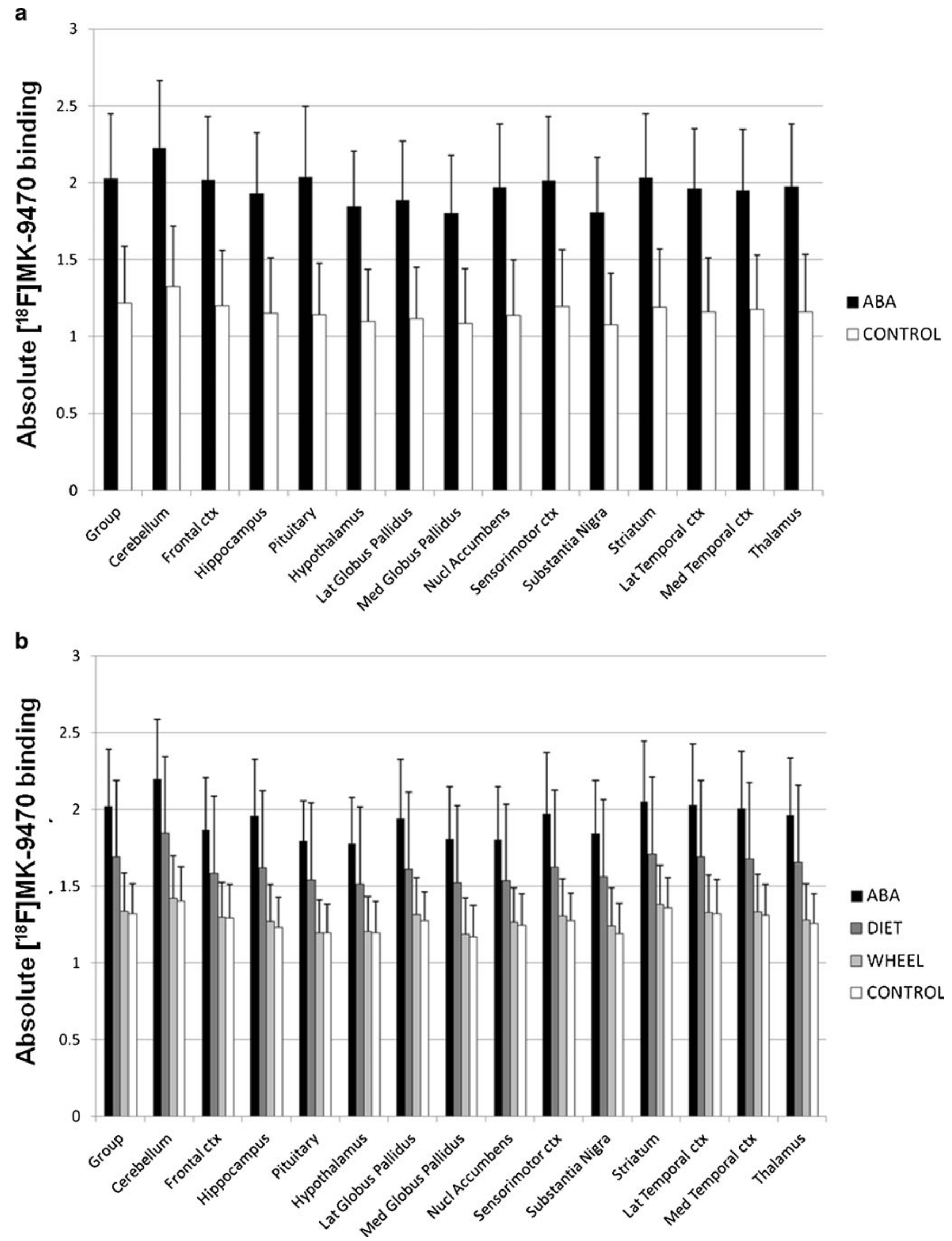
4 Fig. 5 Comparison of absolute $\left[{ }^{18} \mathrm{~F}\right] \mathrm{MK}-9470$ binding in ABA and controls. Bar diagrams showing absolute $\left[{ }^{18} \mathrm{~F}\right] \mathrm{MK}-9470$ binding expressed in mSUV per region of interest in male ABA and CONTROL animals (a) and in female ABA, DIET, WHEEL and CONTROL animals (b). Error bars indicate $1 \mathrm{SD}$

comparison of the DIET group with the CONTROL group (+ $3.4 \%, p_{\text {cluster }}<6.2 \times 10^{-4}$; Fig. $\left.6 \mathrm{c}\right)$. Furthermore, in the experimental set-up used for assessment of reversibility, the comparison of chronic to baseline confirmed the previous increase in relative $\left[{ }^{18} \mathrm{~F}\right] \mathrm{MK}-9470$ binding in the hippocampus, inferior colliculus and visual cortex $\left(>3.4 \%, p_{\text {cluster }}<0.04\right)$, but also reported increased binding in the caudate-putamen and somatosensory and auditory cortices of ABA rats in comparison to CONTROL. After recovery, no significant differences in relative $\left[{ }^{18} \mathrm{~F}\right] \mathrm{MK}$ 9470 binding were detected for both groups in comparison to baseline. Detailed cluster peak locations and $p$ values of categorical and interaction SPM comparisons on relative $\left[{ }^{18} \mathrm{~F}\right] \mathrm{MK}-9470$ binding are given in Table 1.

Regarding the comparison of male and female rats, absolute and relative $\left[{ }^{18} \mathrm{~F}\right] \mathrm{MK}-9470$ binding did not differ between male and female ABA rats $(p>0.9)$ or between male and female CONTROL rats $(p>0.4)$ (Fig. 7). The per cent differences between ABA and CONTROL found in both experimental settings were also not significantly different between male and
Fig. 6 Comparison of relative $\left[{ }^{18} \mathrm{~F}\right] \mathrm{MK}-9470$ binding in ABA and controls. Coronal brain sections showing overlays on the regions where a statistically significant increase (red) in relative $\left[{ }^{18} \mathrm{~F}\right] \mathrm{MK}-9470$ binding was observed between female ABA group compared to CONTROL (a) and WHEEL (b) groups and between female DIET group compared to CONTROL group (c) (figure given at $p_{\text {height }} \leq$ 0.001 uncorrected). Significance is shown with a T statistic colour scale, which corresponds to the level of significance at the voxel level. The distance between the sections is $1.00 \mathrm{~mm}$ with the position relative to bregma (positive values for sections anterior to bregma) on top of the sections in the left corner. Images are oriented in neurological convention

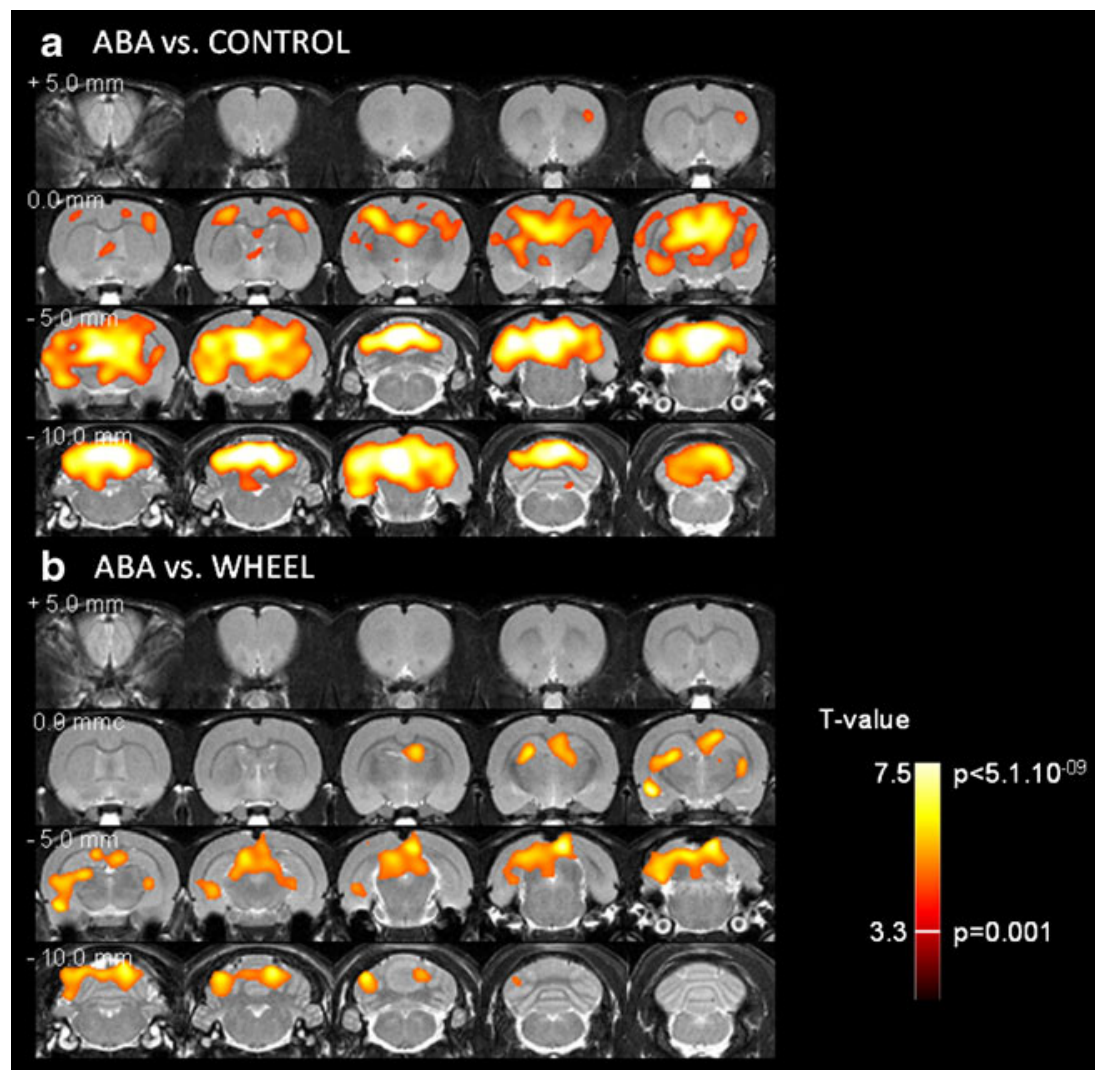

C DIET vs. CONTROL

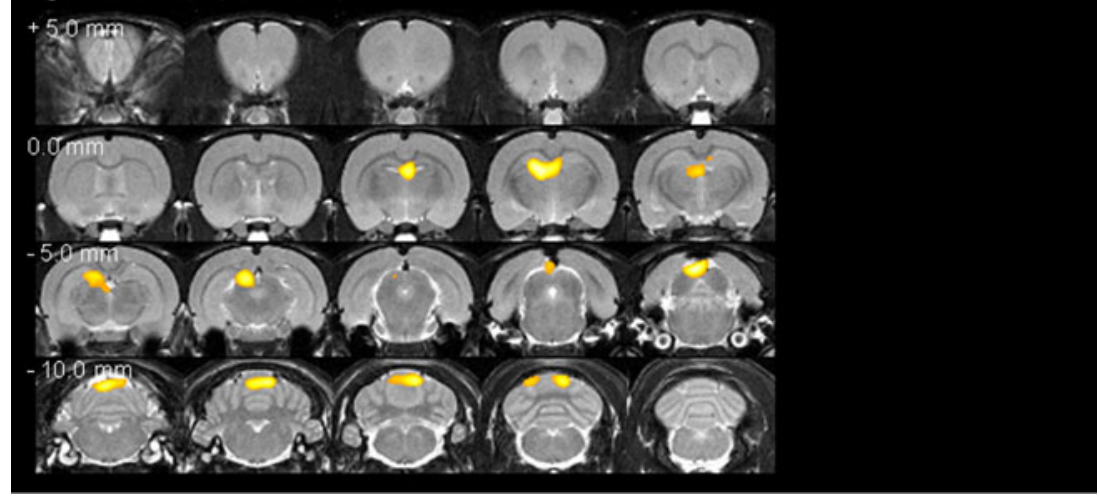


Table 1 Peak locations for the clusters in the categorical and interaction comparisons of relative $\left[{ }^{18} \mathrm{~F}\right] \mathrm{MK}-9470$ binding (at $p_{\text {height }} \leq 0.001$ uncorrected, $\left.\mathrm{k}_{\mathrm{E}}>200\right)$

\begin{tabular}{|c|c|c|c|c|c|c|c|c|c|}
\hline & \multicolumn{2}{|c|}{ Cluster level } & \multicolumn{2}{|c|}{ Voxel level } & \multirow{2}{*}{$\begin{array}{l}\text { Intensity } \\
\text { difference }^{\mathrm{a}}(\%)\end{array}$} & \multicolumn{3}{|c|}{ Structure } & \multirow[t]{2}{*}{ Name } \\
\hline & $p_{\text {corr }}$ & $\mathrm{k}_{\mathrm{E}}$ & $\mathrm{T}$ & $p_{\text {uncorr }}$ & & $\mathrm{x}$ & $\mathrm{y}$ & $\mathrm{z}$ & \\
\hline \multicolumn{10}{|c|}{ Categorical relative $\left[{ }^{18} \mathrm{~F}\right] \mathrm{MK}-9470$ analysis } \\
\hline \multirow[t]{6}{*}{ Female: $\mathrm{ABA}>\mathrm{CONTROL}$} & $<0.001$ & 4,587 & 7.45 & $\begin{array}{l}<0.05 \\
\text { FWE }\end{array}$ & +4.6 & 0.8 & -9.2 & -2.6 & \multirow{6}{*}{$\begin{array}{l}\text { Right hippocampus, } \\
\text { right entorhinal cortex } \\
\text { and inferior colliculus }\end{array}$} \\
\hline & & & 7.10 & $\begin{array}{l}<0.05 \\
\text { FWE }\end{array}$ & & 1.4 & -5.2 & -2.6 & \\
\hline & & & 7.07 & $\begin{array}{l}<0.05 \\
\text { FWE }\end{array}$ & & 2.2 & -2.8 & -3.6 & \\
\hline & $<0.001$ & 1,275 & 7.37 & $\begin{array}{l}<0.05 \\
\text { FWE }\end{array}$ & & 4.8 & -8.4 & -4.6 & \\
\hline & & & 6.01 & $\begin{array}{l}<0.05 \\
\text { FWE }\end{array}$ & & 4.8 & -5.8 & -4.0 & \\
\hline & $=0.001$ & 248 & 6.83 & $\begin{array}{l}<0.05 \\
\text { FWE }\end{array}$ & & 5.0 & -4.4 & -8.0 & \\
\hline \multirow[t]{2}{*}{ Female: ABA $>$ WHEEL } & $<0.001$ & 21,626 & $\begin{array}{l}6.60 \\
5.41\end{array}$ & $\begin{array}{l}<0.001 \\
<0.001\end{array}$ & +2.8 & $\begin{array}{r}5.2 \\
-1.2\end{array}$ & $\begin{array}{l}-4.4 \\
-8.4\end{array}$ & $\begin{array}{l}-8.2 \\
-1.4\end{array}$ & \multirow{2}{*}{$\begin{array}{l}\text { Right hippocampus, left } \\
\text { visual cortex and left } \\
\text { cerebellum }\end{array}$} \\
\hline & & & 5.78 & $<0.001$ & & -1.8 & -10.6 & -2.6 & \\
\hline \multirow[t]{3}{*}{ Female: DIET >CONTROL } & $<0.001$ & 2,557 & $\begin{array}{l}5.51 \\
4.99\end{array}$ & $\begin{array}{l}<0.001 \\
<0.001\end{array}$ & +3.4 & $\begin{array}{r}1.8 \\
-0.2\end{array}$ & $\begin{array}{l}-2.6 \\
-2.4\end{array}$ & $\begin{array}{l}-3.8 \\
-4.0\end{array}$ & \multirow{2}{*}{$\begin{array}{l}\text { Bilateral hippocampus } \\
\text { and superior colliculus }\end{array}$} \\
\hline & & & 4.80 & $<0.001$ & & 1.2 & -5.8 & -3.4 & \\
\hline & $<0.001$ & 2,593 & $\begin{array}{l}5.32 \\
5.07\end{array}$ & $\begin{array}{l}<0.001 \\
<0.001\end{array}$ & & $\begin{array}{r}0.6 \\
-1.2\end{array}$ & $\begin{array}{l}-9.2 \\
-11.4\end{array}$ & $\begin{array}{l}-2.4 \\
-2.0\end{array}$ & $\begin{array}{l}\text { Right inferior colliculus } \\
\text { and left cerebellum }\end{array}$ \\
\hline \multicolumn{10}{|c|}{ Interaction (condition $\mathrm{x}$ subject) relative $\left[{ }^{18} \mathrm{~F}\right] \mathrm{MK}-9470$ analysis } \\
\hline \multirow{6}{*}{$\begin{array}{l}(\text { Chronic baseline })_{\mathrm{ABA}}>(\text { Chronic } \\
\text { baseline })_{\mathrm{CONTROL}}\end{array}$} & 0.03 & 819 & 4.63 & $<0.001$ & +3.6 & -5.6 & -2.6 & -4.4 & \multirow{2}{*}{$\begin{array}{l}\text { Left primary somatosensory } \\
\text { cortex and left caudate- } \\
\text { putamen }\end{array}$} \\
\hline & & & 3.70 & $<0.001$ & & -4.2 & -1.4 & -5.4 & \\
\hline & 0.017 & 967 & $\begin{array}{l}4.48 \\
3.92\end{array}$ & $\begin{array}{l}<0.001 \\
<0.001\end{array}$ & & $\begin{array}{l}6.0 \\
5.0\end{array}$ & $\begin{array}{l}-2.8 \\
-4.4\end{array}$ & $\begin{array}{l}-5.2 \\
-4.6\end{array}$ & \multirow{2}{*}{$\begin{array}{l}\text { Right hippocampus and } \\
\text { right somatosensory, } \\
\text { auditory and visual } \\
\text { cortices }\end{array}$} \\
\hline & & & 3.55 & $<0.001$ & & 5.2 & -5.0 & -2.8 & \\
\hline & 0.036 & 768 & $\begin{array}{l}4.45 \\
4.17\end{array}$ & $\begin{array}{l}<0.001 \\
<0.001\end{array}$ & & $\begin{array}{l}-2.8 \\
-3.2\end{array}$ & $\begin{array}{l}-8.6 \\
-7.4\end{array}$ & $\begin{array}{l}-3.8 \\
-2.4\end{array}$ & \multirow{2}{*}{$\begin{array}{l}\text { Left inferior colliculus } \\
\text { and left visual cortex }\end{array}$} \\
\hline & & & 3.88 & $<0.001$ & & -4.4 & -8.0 & -2.2 & \\
\hline
\end{tabular}

$p_{\text {corr }}$ at cluster level: the chance $(p)$ of finding a cluster with this or a greater size $\left(\mathrm{k}_{\mathrm{E}}\right)$, corrected for search volume, $k_{E}$ cluster extent, $T$ measure of the statistical significance, $p_{\text {uncorr }}$ at voxel level: the chance $(p)$ of finding (under the null hypothesis) a voxel with this or a greater height (T statistic), uncorrected for search volume, $x$ lateral distance in millimetres from the midline (negative values to the right side), $y$ anteroposterior location relative to bregma (negative values: posterior to bregma), $z$ dorsoventral position (based upon the Paxinos stereotactic atlas)

${ }^{a}$ Intensity difference at the voxel level of ABA rats in comparison to controls

female rats $(p>0.2)$. For both ABA and CONTROL groups, body weight on scan day was significantly lower in the female rats compared to male rats $(p<0.00001)$. Also, in female rats, absolute and relative $\left[{ }^{18} \mathrm{~F}\right] \mathrm{MK}-9470$ binding did not differ between rats in early and late phases of the ovarian cycle for WHEEL and CONTROL groups ( $p$ value $>0.2$ ).

Correlation analysis of $\left[{ }^{18} \mathrm{~F}\right] \mathrm{MK}-9470$ PET and behavioural data in ABA

As the above-mentioned differences in behavioural outcomes between ABA and CONTROL were highly significant, combining both groups for correlation analysis of these measurements would only reflect group differences. We therefore only performed correlation analysis between $\left[{ }^{18} \mathrm{~F}\right] \mathrm{MK}-9470$ PET and behavioural data within the ABA group.

In the ABA group, average food intake was positively correlated with body weight on the day of scanning in both genders (Pearson's $r=0.62$ and $r=0.57$, respectively). Average food intake was also negatively correlated with relative body weight loss, but only in male rats $(r=-0.72)$. Moreover, a negative correlation was found between number of wheel rotations and body weight on the day of scanning in male rats $(r=-0.70)$, while a positive correlation of the number of wheel rotations with relative body weight loss was found in female subjects $(r=0.79)$. In the WHEEL group, the number of wheel rotations correlated positively with average food intake $(r=0.82)$. 


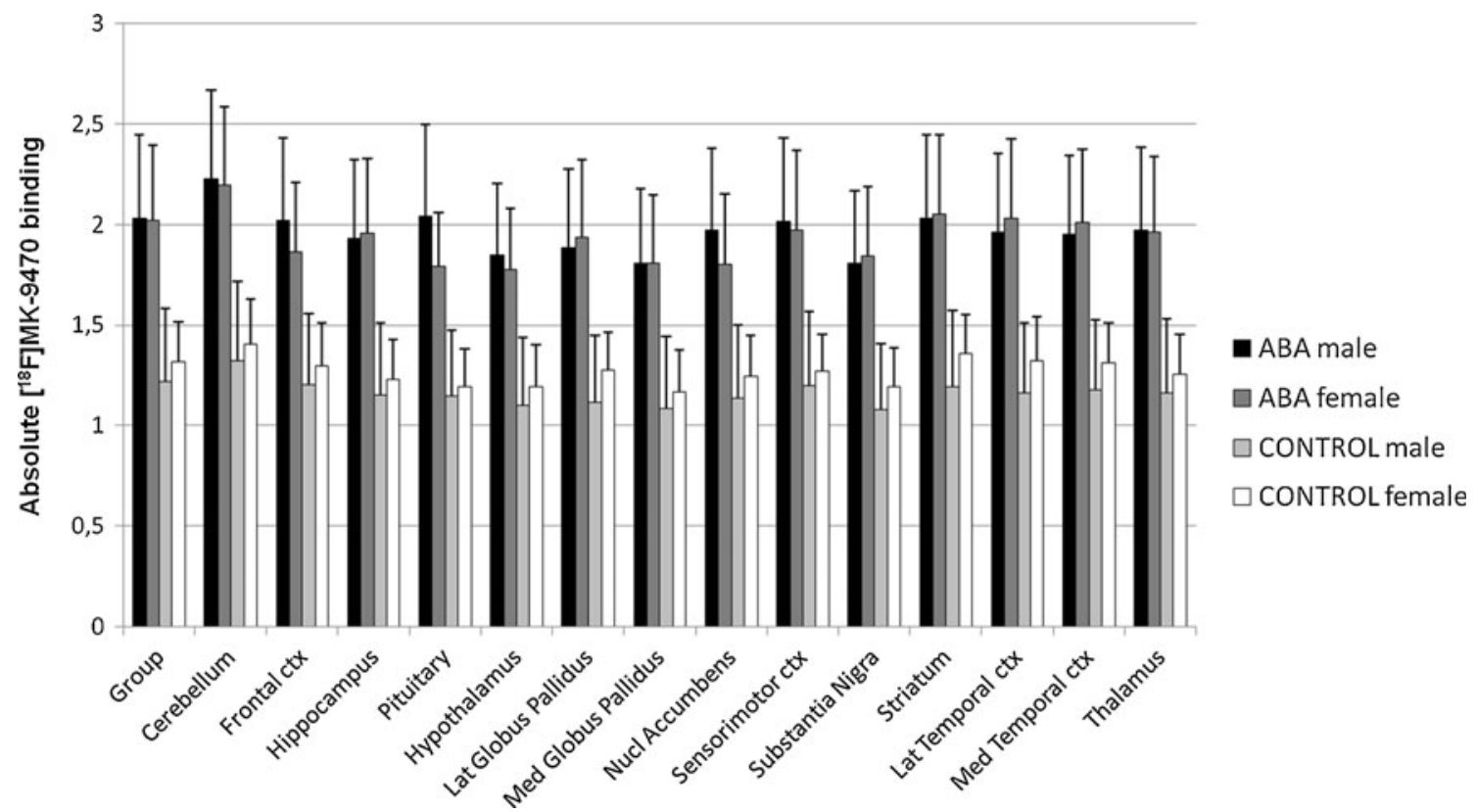

Fig. 7 Comparison of absolute $\left[{ }^{18} \mathrm{~F}\right] \mathrm{MK}-9470$ binding between male and female ABA. Bar diagrams showing absolute $\left[{ }^{18} \mathrm{~F}\right] \mathrm{MK}-9470$ binding expressed in mSUV per region of interest in the ABA and CONTROL groups from both genders. Error bars indicate $1 \mathrm{SD}$

For both male and female ABA rats, no significant correlations were found between absolute or relative $\left[{ }^{18} \mathrm{~F}\right] \mathrm{MK}$ 9470 binding and average food intake, total running activity, weight loss or weight gain.

\section{Discussion}

The aetiology of human AN remains largely unknown, but a complex interplay between genetic, neurobiological and environmental factors appears to play a role. These involve known neurochemical transmission disturbances in the serotonin and dopamine systems, but also a central role of the ECS as modulatory system may be present [35], either directly or through interaction with other neurotransmitter systems involved in eating behaviour.

In this study, we have for the first time characterized CB1 receptor alterations in vivo in the activity-based rodent model of AN using $\left[{ }^{18} \mathrm{~F}\right] \mathrm{MK}-9470$ and small animal PET. Compared to controls, ABA rats showed an in vivo increase in $\mathrm{CB} 1$ receptor availability in all cortical and subcortical areas that normalized again towards baseline values after weight gain. This finding of a widespread transient increase is not surprising considering its role in feeding modulation, in hedonics of food intake and generally in reward [36]. Stimulation of endocannabinoid signalling has an orexigenic effect, but the ECS is also physiologically involved in energy homeostasis of food intake [37]. Previously, compiled preclinical evidence has led to the likeliness of a hypoactive ECS in anorectic conditions based on several indirect arguments. CB1 receptor inactivation via blockade or genetic deletion reduces food intake by suppressing the hedonic aspect [10, 17, 38-41]. CB1 receptor knockout mice also display a lean phenotype and are resistant to diet-induced obesity [42]. In addition, Hanus et al. reported decreased levels of 2-AG in the entire mouse brain, including hypothalamic and hippocampal regions, upon 12 days of food restriction in mice [9]. Fride et al. stated that in the context of prolonged starvation, as seen in AN, decreased levels of 2-AG may aid survival by downregulating the orexigenic effect of EC signalling and reducing appetite and motivation to eat [43]. Although no direct data on the $\mathrm{CB} 1$ receptor status have been reported so far in experimental $\mathrm{AN}$, it is conceivable from our observations that a widespread increase in CB1 receptor availability is in accordance with the above-mentioned impaired endocannabinoid tone, if one assumes that receptor upregulation occurs as a compensatory action due to a chronically hypoactive ECS, as often seen for other receptor systems [44]. Albeit that a decreased endocannabinoid tone could also drive a decrease in $\mathrm{CB} 1$ receptor expression [45] or that the change in CB1 receptor expression occurs independently from changes in the endocannabinoid content [46], a compensatory upregulation is plausible from the large intracellular CB1 receptor reserve previously reported [47]. Other contributing mechanisms such as changes in receptor affinity, in receptor trafficking and in conformational state cannot be excluded, as they cannot be distinguished with PET. Future studies simultaneously measuring brain endocannabinoid levels and CB1 receptor binding using in vivo microdialysis and small animal PET in the 
ABA model are needed to further clarify the above issue. It remains also to be elucidated whether changes in expression and functionality of $\mathrm{CB} 1$ receptors are present in ABA. Nevertheless, the transiency of our finding suggests it to be secondary to ABA and not causal. Of special interest, we have observed a similar finding of a widespread increase in female anorectic patients using the same radioligand and PET [16], suggesting validity of our animal model to mimic human CB1 receptor alterations in $\mathrm{AN}$.

In female $\mathrm{ABA}$, especially hippocampal regions presented a regional increase in $\mathrm{CB} 1$ receptor availability. Our rank order of this increase among the different female conditions (i.e. ABA > DIET $>$ WHEEL and CONTROL) is comparable to the ones of a recent ex vivo study looking at cell proliferation in this model [48]. Barbarich-Marsteller and co-workers observed a profound reduction in cell proliferation of the dorsal hippocampus in $\mathrm{ABA}$ rats using $\mathrm{BrdU}^{+}$and $\mathrm{Ki}-67^{+}$immunohistochemistry that was correlated to body weight and food intake, although the authors stated that various factors relevant to ABA, including food restriction, exercise and sleep deprivation, have an influence on neurogenesis. Of these various factors, especially running activity has been linked to the ECS [49]. Voluntary exercise in rats has been reported to influence hippocampal cell proliferation through modulating the levels of AEA and the density and functionality of $\mathrm{CB} 1$ receptors [49]. Female rats exhibiting ABA also showed elevated levels of $\mathrm{GABA}_{\mathrm{A}}$ receptor subunits $\alpha 4$ and $\delta$ in the hippocampus [50], of which their transmission is known to be modulated via the ECS, but this effect did not show any rank order. We hereby confirmed the prominent role of the hippocampus in another species of female ABA rats than initially reported (Wistar vs Sprague-Dawley rats) [48] and observed no hippocampal effect in the male population. To further strengthen the influence of running activity on $\mathrm{CB} 1$ receptor changes in $\mathrm{ABA}$, we also observed a regional increase in $\mathrm{CB} 1$ receptor binding in the inferior colliculus that is part of the midbrain tectum and controls motor responses [51].

With respect to the observed gender difference, it is conceivable that cannabinoid effects on neuronal processes are in part influenced by oestrogen and progesterone levels, especially in the hippocampus $[52,53]$. However, we were unable to observe any difference in global $\mathrm{CB} 1$ receptor binding between male and female rats of the ABA and CONTROL groups. Also, female rats in the early phase of the menstrual cycle did not differ from those in the late one, at least not under the control conditions. In future studies, cycle phase synchronization and monitoring of cycle-dependent parameters, such as adrenocorticotrophic hormone (ACTH) and cortisol, could totally exclude potential interaction of this variable. Given the involvement of ECS in both eating and motor aspects of AN, multiple control groups should at least be included in these studies. We showed that the association of both seems necessary for significant changes in global and regional CB1 receptor binding.
From a methodological point of view, confounding effects of weight differences on $\left[{ }^{18} \mathrm{~F}\right] \mathrm{MK}-9470$ quantification are unlikely. It is known that large differences in body weight between AN and control subjects may represent differences in $\left[{ }^{18} \mathrm{~F}\right] \mathrm{MK}-9470$ distribution volume, e.g. in fatty tissues. However, we have explicitly validated the use of mSUV prior to study set-up. Full kinetic modelling as the gold quantification standard in a small subset of ABA and control rats showed a positive correlation of $\mathrm{mSUV}$ with total tracer distribution volume $\left(\mathrm{V}_{\mathrm{T}}\right)\left(\mathrm{y}=90 \mathrm{x}-57 ; R^{2}=0.9\right)$. Also, $\mathrm{ABA}$ and control rats showed comparable $\left[{ }^{18} \mathrm{~F}\right] \mathrm{MK}-9470$ percentage fractions in arterial samples $(62.2 \pm 3.4 \%$ vs $58.4 \pm 9.5 \%$ and $12.8 \pm$ $7.4 \%$ vs $7.1 \pm 0.5 \%$ for ABA and control at 3 and 40 min postinjection, respectively), and non-parametric analysis did not detect significant differences in the AUC of the metabolitecorrected plasma input functions. Furthermore, the mSUV parameter is normalized by animal weight; consequently the systemically lower weight of ABA rats would imply an underestimation of $\mathrm{CB} 1$ receptor availability and does therefore not explain the global increase observed in this manuscript. In addition, we did not observe any difference in $\left[{ }^{18} \mathrm{~F}\right] \mathrm{MK}-9470$ uptake between male and female rats within each condition, even though their body weight differed significantly.

\section{Conclusion}

In vivo cerebral mapping of a well-known rodent model for AN using $\left[{ }^{18} \mathrm{~F}\right] \mathrm{MK}-9470$ small animal PET points to a widespread transient disturbance of the endocannabinoid transmission, specific for $\mathrm{CB} 1$ receptors and especially affecting the hippocampus in female subjects, that normalized upon recovery. Our findings also demonstrate molecular validity of the $\mathrm{ABA}$ model to mimic $\mathrm{CB} 1$ receptor alterations in human $\mathrm{AN}$.

Acknowledgments Merck \& Co, Inc. is acknowledged for the availability of the $\left[{ }^{18} \mathrm{~F}\right] \mathrm{MK}-9470$ precursor, and for their critical revision of this manuscript and their suggestions for improvement. The authors thank Peter Vermaelen and Ann Van Santvoort for their assistance in data acquisition, as well as the Leuven PET radiopharmacy team for tracer preparations. Financial support of the Research Council of the Katholieke Universiteit Leuven (OT/05/58), the Fund for Scientific Research, Flanders, Belgium (FWO/G.0548.06), the K.U. Leuven Molecular Small Animal Imaging Center $(\mathrm{KUL}$ EF/05/08) is gratefully acknowledged. Cindy Casteels and Kris van Kuyck are supported by a postdoctoral mandate of the Flemish Fund for Scientific Research. Koen Van Laere is a senior clinical investigator of the Flemish Fund for Scientific Research.

Conflicts of interest None.

\section{References}

1. Fairburn CG, Harrison PJ. Eating disorders. Lancet 2003;361:407-16.

2. American Psychiatric Association. Treatment of patients with eating disorders, third edition. American Psychiatric Association. Am J Psychiatry 2006; 163:4-54. 
3. Katona I, Freund TF. Endocannabinoid signaling as a synaptic circuit breaker in neurological disease. Nat Med 2008;14:923-30.

4. Cota D, Steiner MA, Marsicano G, Cervino C, Herman JP, Grübler Y, et al. Requirement of cannabinoid receptor type 1 for the basal modulation of hypothalamic-pituitary-adrenal axis function. Endocrinology 2007;148:1574-81.

5. Solinas M, Yasar S, Goldberg SR. Endocannabinoid system involvement in brain reward processes related to drug abuse. Pharmacol Res 2007;56:393-405.

6. Wilson RI, Nicoll RA. Endocannabinoid signaling in the brain. Science 2002;296:678-82.

7. Di Marzo V, Bifulco M, De Petrocellis L. The endocannabinoid system and its therapeutic exploitation. Nat Rev Drug Discov 2004;3:771-84.

8. Monteleone P, Matias I, Martiadis V, De Petrocellis L, Maj M, Di Marzo V. Blood levels of the endocannabinoid anandamide are increased in anorexia nervosa and in binge-eating disorder, but not in bulimia nervosa. Neuropsychopharmacology 2005;30:1216-21.

9. Hanus L, Avraham Y, Ben-Shushan D, Zolotarev O, Berry EM, Mechoulam R. Short-term fasting and prolonged semistarvation have opposite effects on 2-AG levels in mouse brain. Brain Res 2003;983: 144-51.

10. Wiley JL, Burston JJ, Leggett DC, Alekseeva OO, Razdan RK, Mahadevan A, et al. CB1 cannabinoid receptor-mediated modulation of food intake in mice. Br J Pharmacol 2005;145:293-300.

11. Siegfried Z, Kanyas K, Latzer Y, Karni O, Bloch M, Lerer B, et al. Association study of cannabinoid receptor gene (CNR1) alleles and anorexia nervosa: differences between restricting and binging/ purging subtypes. Am J Med Genet B Neuropsychiatr Genet 2004;125B:126-30.

12. Monteleone P, Bifulco M, Di Filippo C, Gazzerro P, Canestrelli B, Monteleone F, et al. Association of CNR1 and FAAH endocannabinoid gene polymorphisms with anorexia nervosa and bulimia nervosa: evidence for synergistic effects. Genes Brain Behav 2009;8:728-32.

13. Beal JE, Olson R, Lefkowitz L, Laubenstein L, Bellman P, Yangco B, et al. Long-term efficacy and safety of dronabinol for acquired immunodeficiency syndrome-associated anorexia. J Pain Symptom Manage 1997;14:7-14.

14. Arias Horcajadas F. Cannabinoids in eating disorders and obesity. Mol Neurobiol 2007;36:113-28.

15. Gross H, Ebert MH, Faden VB, Goldberg SC, Kaye WH, Caine ED, et al. A double-blind trial of delta 9-tetrahydrocannabinol in primary anorexia nervosa. J Clin Psychopharmacol 1983;3:165-71.

16. Gérard N, Pieters G, Goffin K, Bormans G, Van Laere K. Brain type 1 cannabinoid receptor availability in patients with anorexia and bulimia nervosa. Biol Psychiatry 2011;70:777-84.

17. Rorato R, Reis WL, de Carvalho BB, Antunes-Rodrigues J, Elias LL. Cannabinoid $\mathrm{CB}(1)$ receptor restrains accentuated activity of hypothalamic corticotropin-releasing factor and brainstem tyrosine hydroxylase neurons in endotoxemia-induced hypophagia in rats. Neuropharmacology 2012;63:154-60.

18. Burns HD, Van Laere K, Sanabria-Bohórquez S, Hamill TG, Bormans G, Eng WS, et al. [18F]MK-9470, a positron emission tomography (PET) tracer for in vivo human PET brain imaging of the cannabinoid1 receptor. Proc Natl Acad Sci U S A 2007;104:9800-5.

19. Hillebrand JJ, Koeners MP, de Rijke CE, Kas MJ, Adan RA. Leptin treatment in activity-based anorexia. Biol Psychiatry 2005;58:165-71.

20. Hillebrand JJ, Heinsbroek AC, Kas MJ, Adan RA. The appetite suppressant d-fenfluramine reduces water intake, but not food intake, in activity-based anorexia. J Mol Endocrinol 2006;36:153-62.

21. Dixon DP, Ackert AM, Eckel LA. Development of, and recovery from, activity-based anorexia in female rats. Physiol Behav 2003;80:273-9.

22. Barbarich-Marsteller NC, Marsteller DA, Alexoff DL, Fowler JS, Dewey SL. MicroPET imaging in an animal model of anorexia nervosa. Synapse 2005;57:85-90.
23. van Kuyck K, Casteels C, Vermaelen P, Bormans G, Nuttin B, Van Laere K. Motor- and food-related metabolic cerebral changes in the activity-based rat model for anorexia nervosa: a voxel-based microPET study. Neuroimage 2007;35:214-21.

24. Marcondes FK, Bianchi FJ, Tanno AP. Determination of the estrous cycle phases of rats: some helpful considerations. Braz J Biol 2002;62:609-14.

25. Casteels C, Koole M, Celen S, Bormans G, Van Laere K. Preclinical evaluation and quantification of [(18)F]MK-9470 as a radioligand for PET imaging of the type 1 cannabinoid receptor in rat brain. Eur $\mathrm{J}$ Nucl Med Mol Imaging 2012;39:1467-77.

26. Casteels C, Bormans G, Van Laere K. The effect of anaesthesia on [(18)F]MK-9470 binding to the type 1 cannabinoid receptor in the rat brain. Eur J Nucl Med Mol Imaging 2010;37:1164-73.

27. Boellaard R, van Lingen A, Lammertsma AA. Experimental and clinical evaluation of iterative reconstruction (OSEM) in dynamic PET: quantitative characteristics and effects on kinetic modeling. J Nucl Med 2001;42:808-17.

28. Hoekzema E, Rojas S, Herance R, Pareto D, Abad S, Jiménez X, et al. [(11)C]-DASB microPET imaging in the aged rat: frontal and meso-thalamic increases in serotonin transporter binding. Exp Gerontol 2011;46:1020-5.

29. Thie JA, Hubner KF, Isidoro FP, Smith GT. A weight index for the standardized uptake value in 2-deoxy-2-[F-18]fluoro-D-glucose-positron emission tomography. Mol Imaging Biol 2007;9:91-8.

30. Sanabria-Bohórquez SM, Hamill TG, Goffin K, De Lepeleire I, Bormans G, Burns HD, et al. Kinetic analysis of the cannabinoid-1 receptor PET tracer [(18)F]MK-9470 in human brain. Eur J Nucl Med Mol Imaging 2010;37:920-33.

31. Goffin K, Bormans G, Casteels C, Bosier B, Lambert DM, Grachev ID, et al. An in vivo [(18)F]MK-9470 microPET study of type 1 cannabinoid receptor binding in Wistar rats after chronic administration of valproate and levetiracetam. Neuropharmacology 2008;54:1103-6.

32. Casteels C, Vermaelen P, Nuyts J, Van Der Linden A, Baekelandt V, Mortelmans L, et al. Construction and evaluation of multitracer small-animal PET probabilistic atlases for voxel-based functional mapping of the rat brain. J Nucl Med 2006;47:1858-66.

33. Casteels C, Vandeputte C, Rangarajan JR, Dresselaers T, Riess O, Bormans $\mathrm{G}$, et al. Metabolic and type 1 cannabinoid receptor imaging of a transgenic rat model in the early phase of Huntington disease. Exp Neurol 2011;229:440-9.

34. Herkenham M, Lynn AB, Little MD, Johnson MR, Melvin LS, de Costa BR, et al. Cannabinoid receptor localization in brain. Proc Natl Acad Sci U S A 1990;87:1932-6.

35. Matias I, Di Marzo V. Endocannabinoids and the control of energy balance. Trends Endocrinol Metab 2007;18:27-37.

36. Solinas M, Goldberg SR, Piomelli D. The endocannabinoid system in brain reward processes. Br J Pharmacol 2008;154:369-83.

37. Di Marzo V, Ligresti A, Cristino L. The endocannabinoid system as a link between homoeostatic and hedonic pathways involved in energy balance regulation. Int J Obes (Lond) 2009;33 Suppl 2:S18-24.

38. Di Marzo V, Goparaju SK, Wang L, Liu J, Bátkai S, Járai Z, et al. Leptin-regulated endocannabinoids are involved in maintaining food intake. Nature 2001;410:822-5.

39. McLaughlin PJ, Winston K, Swezey L, Wisniecki A, Aberman J, Tardif DJ, et al. The cannabinoid CB1 antagonists SR 141716A and AM 251 suppress food intake and food-reinforced behavior in a variety of tasks in rats. Behav Pharmacol 2003;14:583-8.

40. Rowland NE, Mukherjee M, Robertson K. Effects of the cannabinoid receptor antagonist SR 141716, alone and in combination with dexfenfluramine or naloxone, on food intake in rats. Psychopharmacology (Berl) 2001;159:111-6.

41. De Vry J, Schreiber R, Eckel G, Jentzsch KR. Behavioral mechanisms underlying inhibition of food-maintained responding by the cannabinoid receptor antagonist/inverse agonist SR141716A. Eur J Pharmacol 2004;483:55-63. 
42. Ravinet Trillou C, Delgorge C, Menet C, Arnone M, Soubrié P. CB1 cannabinoid receptor knockout in mice leads to leanness, resistance to diet-induced obesity and enhanced leptin sensitivity. Int J Obes Relat Metab Disord 2004;28:640-8.

43. Fride E, Bregman T, Kirkham TC. Endocannabinoids and food intake: newborn suckling and appetite regulation in adulthood. Exp Biol Med (Maywood) 2005;230:225-34.

44. Riad M, Zimmer L, Rbah L, Watkins KC, Hamon M, Descarries L. Acute treatment with the antidepressant fluoxetine internalizes 5HT1A autoreceptors and reduces the in vivo binding of the PET radioligand $[18 \mathrm{~F}] \mathrm{MPPF}$ in the nucleus raphe dorsalis of rat. $\mathrm{J}$ Neurosci 2004;24:5420-6.

45. Romero J, García L, Fernández-Ruiz JJ, Cebeira M, Ramos JA. Changes in rat brain cannabinoid binding sites after acute or chronic exposure to their endogenous agonist, anandamide, or to delta 9-tetrahydrocannabinol. Pharmacol Biochem Behav 1995;51:731-7.

46. Hill MN, Patel S, Carrier EJ, Rademacher DJ, Ormerod BK, Hillard CJ, et al. Downregulation of endocannabinoid signaling in the hippocampus following chronic unpredictable stress. Neuropsychopharmacology 2005;30:508-15.

47. Gifford AN, Bruneus M, Gatley SJ, Lan R, Makriyannis A, Volkow ND. Large receptor reserve for cannabinoid actions in the central nervous system. J Pharmacol Exp Ther 1999;288:478-83.
48. Barbarich-Marsteller NC, Fornal CA, Takase LF, Bocarsly ME, Arner C, Walsh BT, et al. Activity-based anorexia is associated with reduced hippocampal cell proliferation in adolescent female rats. Behav Brain Res 2013;236:251-7.

49. Hill MN, Titterness AK, Morrish AC, Carrier EJ, Lee TT, GilMohapel J, et al. Endogenous cannabinoid signaling is required for voluntary exercise-induced enhancement of progenitor cell proliferation in the hippocampus. Hippocampus 2010;20:513-23.

50. Aoki C, Sabaliauskas N, Chowdhury T, Min JY, Colacino AR, Laurino $\mathrm{K}$, et al. Adolescent female rats exhibiting activitybased anorexia express elevated levels of $\operatorname{GABA}(\mathrm{A})$ receptor alpha4 and delta subunits at the plasma membrane of hippocampal CA1 spines. Synapse 2012;66:391-407.

51. Schenberg LC, Póvoa RM, Costa AL, Caldellas AV, Tufik S, Bittencourt AS. Functional specializations within the tectum defense systems of the rat. Neurosci Biobehav Rev 2005;29: 1279-98.

52. Coddington E, Lewis C, Rose JD, Moore FL. Endocannabinoids mediate the effects of acute stress and corticosterone on sex behavior. Endocrinology 2007;148:493-500.

53. Mani SK, Mitchell A, O’Malley BW. Progesterone receptor and dopamine receptors are required in delta 9-tetrahydrocannabinol modulation of sexual receptivity in female rats. Proc Natl Acad Sci U S A 2001;98:1249-54. 